\title{
Strain Rate Effect on the Progressive Collapse Analysis of RC Frame Structure under Earthquake
}

\author{
Wenming Wang (iD \\ School of Civil Engineering, Shandong Jianzhu University, Jinan 250101, China \\ Correspondence should be addressed to Wenming Wang; wangwenmingmr@sdjzu.edu.cn
}

Received 16 August 2019; Revised 29 November 2019; Accepted 30 December 2019; Published 22 January 2020

Academic Editor: Hugo C. Biscaia

Copyright (C) 2020 Wenming Wang. This is an open access article distributed under the Creative Commons Attribution License, which permits unrestricted use, distribution, and reproduction in any medium, provided the original work is properly cited.

\begin{abstract}
The strain rate effect can influence the seismic responses of reinforced concrete (RC) structures because the constitutive relationship of concrete and rebar is rate-dependent. This paper carries out progressive collapse analysis to research the influence of strain rate effects on collapse-resistant capacity, collapse mode, and collapse path of the $\mathrm{RC}$ frame structure. A progressive collapse simulation program for the reinforced concrete (RC) structure with a static and dynamic constitutive relationship is coded individually using the user subroutine VUMAT and then implemented in the advanced finite element program ABAQUS. The good agreement between experimental and simulation results proves that the coded subroutine is reliable. With the coded subroutine, by conducting progressive collapse analyses of a four-story RC frame structure under earthquake, the effect of strain rate on the response is investigated. The numerical results demonstrate that the collapse-resistant capacity of the structure is underestimated when the strain rate effect is neglected. It is shown that strain rate effects influence the collapse mode and collapse path of the structure. Therefore, strain rate effects should be considered in the progressive collapse analysis of the RC frame structure.
\end{abstract}

\section{Introduction}

The strain rate of steel and concrete at critical sections of beams and columns can reach as high as $10^{-1} \cdot \mathrm{s}^{-1}$ under earthquake. The experimental results have shown that both steel and concrete are rate-sensitive materials, which have different mechanical properties under different strain rates. Abrams discovered that the compressive strength of concrete depends on the loading rate [1]. After that, lots of researchers studied the mechanical properties of concrete under dynamic loading $[2,3]$. The compressive mechanical property of concrete at different strain rates were systematically reviewed by Bischoff and Perry [4]. Lots of results show that the compressive strength, elasticity modulus, and energy-dissipating capacity increase with the rise of strain rate. Under tensile condition, the tests are difficult to conduct. Due to the influence of test condition and material properties, characteristics of concrete under tensile force suffer from obvious discreteness. Malva and Ross systematically reviewed the tensile properties of concrete under tensile condition. Generally, test results show that the tensile strength of concrete increases obviously with the rise of strain rate, and the raise of elasticity modulus is not apparent [5]. As early as 1909, Ludwik discovered that the mechanical property of steel is rate-dependent [6]. After that, lots of researchers conducted tests to study its dynamic property [7-9]. It is concluded that the yield and tensile strength are all enhanced with adding of strain rate, and the strain rate effect of yield strength is relatively more obvious. The difference of elasticity modulus under different loading rates is not observed.

Tiny difference on elasticity modulus of concrete and no difference on that of steel are observed under different loading rates. Therefore, the strain rate effect in the elastic phase can be neglected for RC structures under earthquake. In the plastic stage, the strain rate effect has an obvious influence on the behavior of members. Many researchers investigated the influence of strain rate on the response of components and structures. By adopting rate-dependent moment-curvature relationships, the influence of strain-rate 
sensitivity of concrete and reinforcing steel on the global seismic response of reinforced concrete (RC) structures in the plastic phase is appreciated [10]. Results show that strength reserve of the structure system is experienced when the strain rate effect is accounted for. Li et al. investigated the influence of loading rate on the bearing ability, ductility, stiffness, failure mode, and energy absorption of beam specimens by conducting dynamic tests [11]. The dynamic behaviors of columns were studied by Wang et al. [12]. It can be seen from the beam and column tests that as the loading rate increases the bearing capacity and equivalent damping augment, the ductility decreases, and the stiffness degradation is more significant. The beam with lower material strength is more sensitive to loading rate. Systematic experimental tests including material and components, and numerical simulations of a three-story RC structure by using a coded three-dimensional rate-dependent fiber beam-column element subroutine are conducted to investigate the strain rate effects on the seismic response of RC structures [13]. It shows that the seismic responses of the structure are overestimated when the strain rate effect is neglected, and the simulated results obtained from the rate-dependent element model can be more in agreement with the results from the shaking table test.

Over the past decades, there have been lots of cases where RC frame structures around the world have experienced total or partial collapse under strong earthquakes. Thus, it is necessary to study not only the seismic response of RC frame structures in elastic and plastic phases, but also their collapse process. Progressive collapse analysis is a wellunderstood physical occurrence in which loss of local loadbearing capacity propagates through a system, precipitating the complete collapse or a major portion of it [14]. Vulnerable points, collapse mode, and capacity of a structure can be evaluated by it, which can be used for the design of new buildings or for evaluating existing structures. This has led to directing increased attention to the progressive collapse analysis under earthquake. However, there is little research about the strain rate effect on the progressive collapse pattern of the RC frame structure.

This paper is organized as follows. In Section 2, progressive collapse analysis methods are introduced. Then, a collapse simulation program that can consider the strain rate effect is introduced in Section 3. In Section 4, the strain rate effect on the progressive collapse of a four-story RC frame structure under earthquake is studied. Finally, a summary is given in Section 5, along with some concluding remarks.

\section{Progressive Collapse Analysis Methods}

Numerical simulation of progressive collapse, including the material and geometrical nonlinearity, contact and collision between elements, losing the load-bearing capacity of elements, and so on, is one of the most complicated problems in structural engineering. Numerical analytical methods used for the collapse analysis include the discrete element method (DEM), combined finite-discrete element method (CFDEM), applied element method (AEM), finite particle method (FPM), and finite element method (FEM).
The DEM was initially developed for the study of jointed rock systems by Cundall and Stract [15], in which the individual material element was considered to be separate and was connected only along its boundaries by the frictional contact. Due to its capacity to explicitly represent the motion of multiple and intersecting discontinuities, the DEM is particularly suitable for the analysis of a structure consisting of granular and particulate materials, and advantageous to deal with collision problems [16-18]. The CFDEM is a recently developed numerical method aimed at modelling fracturing and failing elements, which can concentrate the advantages of FEM and DEM and has been applied to a wide range of engineering problems $[19,20]$. The AEM, which can predict the behaviors of a structure from zero loading to collapse in a reasonable CPU time, is an innovative method adopting the concept of discrete cracking [21-23]. The FPM was presented for the study of space steel structures by Yu and Luo [24, 25], which is based on vector mechanics. Not only material and geometrical nonlinearity, but also fracture, contact, and collision during the collapse process can be modeled. The FEM, based on continuum mechanics, is the most widely used method in structure engineering. It is very effective for solving nonlinear problems by using a reasonable constitutive relationship and a failure criterion [26, 27].

Due to complexity and difficulty of progressive collapse analysis, it is difficult to be applied in current civil engineering, especially for high-rise buildings. The DEM is difficult to be used for large and complex structures due to its low efficiency and modelling complexity. The CFDEM is difficult to be used because of that each particular application requires the development of specific algorithmic procedures. Owing to the computational efficiency and modelling problem, the AEM has not been used for high-rise RC structures. The FPM is still under investigation, and has not been used for the RC structure. Current civil engineering practice prefers to use the FEM for structural analysis. With the dramatic developments in computer performances, the method can be used in the solution of large scale and complex industrial problems. Furthermore, there are lots of commercial FEM software that can be mastered easily by engineers. The FEM has been widely used for the progressive collapse analysis of multi-story and high-rise RC buildings.

\section{Progressive Collapse Simulation Subroutine considering Strain Rate Effect}

In our previous work [28], a progressive collapse simulation subroutine is coded, which can be used for the collapse analysis of a steel structure [29], such as transmission towerline system. In this paper, a three-dimensional rate-dependent fiber beam-column element model based on the ABAQUS analysis platform is developed, in which the strain rate effect can be included. The coded subroutine can be used for the collapse analysis of the reinforced concrete frame structure. The constitutive relationships of concrete and rebar are based on the "Code for Design of Concrete Structures" (GB 50010-2010) [30]. According to the failure criterion of material, the element that loses the load-bearing capacity can be "killed" and removed from the model. 
3.1. Constitutive Model for Concrete. The constitutive model for the concrete is shown in Figure 1. If the strain exceeds the fracture value, the concrete loses the tensile capacity. If the strain exceeds the ultimate compressive value, the element loses the load-bearing capacity. Once the element loses the bearing ability, according to the "birth-death element" method, the element is removed from the model.

For the uniaxial compressive loading, the stress-strain relationship is as follows:

$$
\begin{aligned}
& \sigma= \begin{cases}1-d_{c} E_{c} \varepsilon, & \varepsilon \leq \varepsilon_{\mathrm{cu}}, \\
\text { remove element, } & \varepsilon>\varepsilon_{\mathrm{cu}} .\end{cases} \\
& \varepsilon_{\mathrm{cu}}= \begin{cases}0.0033, & f_{\mathrm{cu}, k} \leq 50, \\
0.0033-\left(f_{\mathrm{cu}, k}-50\right) \times 10^{-5}, & f_{\mathrm{cu}, k} \leq 50 .\end{cases} \\
& d_{c}= \begin{cases}1-\rho_{c}\left[\alpha_{a}+\left(3-2 \alpha_{a}\right) x+\left(\alpha_{a}-2\right) x^{2}\right], & \text { if } x \leq 1, \\
1-\frac{\rho_{c}}{\alpha_{d}(x-1)^{2}+x}, & \text { if } x>1,\end{cases} \\
& x=\frac{\varepsilon}{\varepsilon_{c}}, \\
& \rho_{c}=\frac{f_{c}^{*}}{E_{c} \varepsilon_{c}},
\end{aligned}
$$

where $\varepsilon$ and $\sigma$ are the strain and stress; $d_{c}$ is the damage evolution parameter for the uniaxial compressive loading; $E_{c}$ is the elastic modulus; $\varepsilon_{\mathrm{cu}}$ is the ultimate compressive strain, which can be determined from experimental data or computed as equation (2); $f_{\mathrm{cu}, k}$ is the characteristic value of cubic compressive strength; $\alpha_{a}$ and $\alpha_{d}$ are the parameter values for rising and descending segments in the uniaxial compression stress-strain curve; $f_{c}^{*}$ is the uniaxial compression strength; and $\varepsilon_{c}$ is the peak value of compression strain corresponding to $f_{c}^{*}$.

For uniaxial tensile loading, the stress-strain relationship is written as follows:

$$
\begin{aligned}
& \sigma= \begin{cases}\left(1-d_{t}\right) E_{c} \varepsilon, & \text { if } \varepsilon \leq \varepsilon_{f}, \\
0, & \text { if } \varepsilon>\varepsilon_{f} .\end{cases} \\
& d_{t}= \begin{cases}1-\rho_{t}\left[1.2-0.2 x^{5}\right], & \text { if } x \leq 1, \\
1-\frac{\rho_{t}}{\alpha_{t}(x-1)^{1.7}+x}, & \text { if } x>1 .\end{cases} \\
& x=\frac{\varepsilon}{\varepsilon_{t},} \\
& \rho_{c}=\frac{f_{t}^{*}}{E_{c} \varepsilon_{t},}
\end{aligned}
$$

where $\varepsilon_{f}$ is the fracture strain; $d_{t}$ is the damage evolution parameter for the uniaxial tensile loading; $f_{t}^{*}$ is the uniaxial

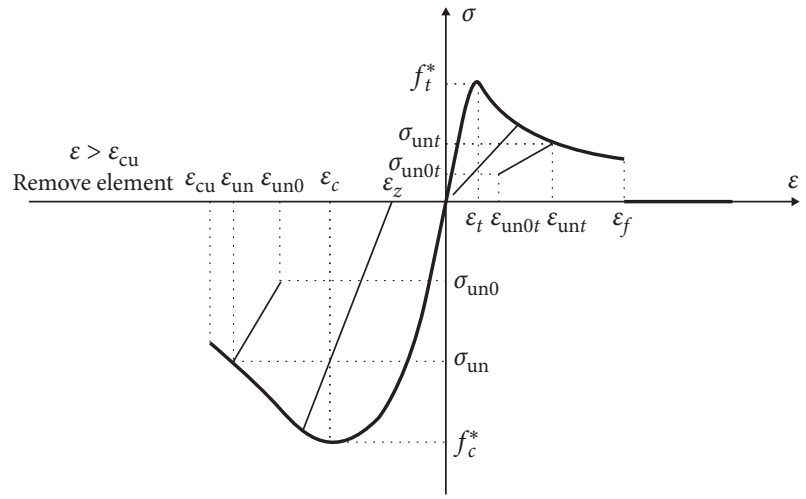

FIgURE 1: Constitutive model for concrete.

tensile strength; and $\varepsilon_{t}$ is the peak value of tensile strain corresponding to $f_{t}^{*}$.

For the cyclic compressive loading, the stress-strain relationship is expressed as

$$
\begin{aligned}
\sigma & =E_{r}\left(\varepsilon-\varepsilon_{z}\right), \\
E_{r} & =\frac{\sigma_{\mathrm{un} 0}-\sigma_{\mathrm{un}}}{\varepsilon_{\mathrm{un} 0}-\varepsilon_{\mathrm{un}}}, \\
\varepsilon_{z} & =\varepsilon_{\mathrm{un}}-\frac{\left(\varepsilon_{\mathrm{un}}+\varepsilon_{\mathrm{ca}}\right) \sigma_{\mathrm{un}}}{\sigma_{\mathrm{un}}+E_{c} \varepsilon_{\mathrm{ca}}}, \\
\varepsilon_{\mathrm{ca}} & =\max \left(\frac{\varepsilon_{c}}{\varepsilon_{c}+\varepsilon_{\mathrm{un}}}, \frac{0.09 \varepsilon_{\mathrm{un}}}{\varepsilon_{c}}\right) \sqrt{\varepsilon_{c} \varepsilon_{\mathrm{un}}},
\end{aligned}
$$

where $E_{r}$ is the secant modulus; $\varepsilon_{z}$ is the residual strain; $\sigma_{\text {un } 0}$ and $\varepsilon_{\text {un } 0}$ are the stress and strain of the ending point of uninstall curve; $\sigma_{\text {un }}$ and $\varepsilon_{\text {un }}$ are the stress and strain of the starting point of uninstall curve; and $\varepsilon_{\mathrm{ca}}$ is the additional strain.

For the cyclic tensile loading, the stress-strain relationship is

$$
\begin{aligned}
\sigma & =E_{\mathrm{rt}}\left(\varepsilon-\varepsilon_{z}\right), \\
E_{\mathrm{rt}} & =\frac{\sigma_{\mathrm{unt}}-\sigma_{\mathrm{un} 0 t}}{\varepsilon_{\mathrm{unt}}-\varepsilon_{\mathrm{un} 0 t}},
\end{aligned}
$$

where $E_{\mathrm{rt}}$ is the secant modulus; $\sigma_{\mathrm{un} 0 t}$ and $\varepsilon_{\mathrm{un} 0 t}$ are the stress and strain of the ending point of the uninstall curve; and $\sigma_{\text {unt }}$ and $\varepsilon_{\text {unt }}$ are the stress and strain of the starting point of the uninstall curve, respectively.

With considering the strain rate effect, the uniaxial compression strength under dynamic loading can be calculated as follows [31]:

$$
f_{\mathrm{cd}}=\left(1.327+0.068 \lg \dot{\varepsilon}_{c}\right) f_{\mathrm{cs}},
$$

where $f_{\mathrm{cd}}$ is the dynamic compression strength; $f_{\mathrm{cs}}$ is the quasi-static strength; the quasi-static strain rate takes the value $10^{-5} / \mathrm{s}$; and $\dot{\varepsilon}_{c}$ is the strain rate.

Under dynamic loading, the tensile strength of concrete can be calculated as follows [32] 


$$
f_{\mathrm{td}}=\left(1.0+0.057 \lg \frac{\dot{\varepsilon}_{t}}{\dot{\varepsilon}_{t s}}\right) f_{\mathrm{ts}},
$$

where $f_{\text {td }}$ and $f_{\text {ts }}$ are the dynamic and quasi-static yield strength, respectively; $\dot{\varepsilon}_{t}$ is the strain rate; and $\dot{\varepsilon}_{\mathrm{ts}}$ is the quasistatic strain rate (here $\dot{\varepsilon}_{\mathrm{ts}}=10^{-5} / \mathrm{s}$ ).

3.2. Constitutive Model for Rebar. The elastic-perfectly plastic material model is used for the rebar, which is shown in Figure 2. If the strain exceeds the ultimate strain, the element loses the load-bearing capacity. According to the "birth-death element" method, once the strain exceeds the ultimate strain, the element is removed from the model; according to the proposed method, once the strain exceeds the ultimate strain, the stiffness of the element is equal to zero while the mass is still retained.

For the uniaxial loading, the stress-strain relationship of rebar is as follows:

$$
\sigma= \begin{cases}E_{s}, & \text { if } \varepsilon \leq \varepsilon_{y}, \\ f_{y}, & \text { if } \varepsilon_{y} \leq \varepsilon \leq \varepsilon_{u}, \\ \text { remove element, } & \text { if } \varepsilon>\varepsilon_{u},\end{cases}
$$

where $E_{s}$ is the elastic modulus of steel; $\varepsilon_{y}$ is the yield strain; $f_{y}$ is the yield strength; and $\varepsilon_{u}$ is the ultimate strain.

For the cyclic loading, the stress-strain relationship is expressed as

$$
\sigma=\sigma_{a}+E_{s}\left(\varepsilon-\varepsilon_{a}\right),
$$

where $\sigma_{a}$ and $\varepsilon_{a}$ are the stress and strain of the starting point in the uninstall curve.

In the seismic strain rate range, the dynamic strength of steel can be calculated as follows [9]

$$
\begin{aligned}
f_{\mathrm{yd}} & =\left(1+c_{f} \lg \frac{\dot{\varepsilon}}{\dot{\varepsilon}_{0}}\right) f_{\mathrm{ys}}, \\
c_{f} & =0.1709-3.289 \times 10^{-4} f_{\mathrm{ys}},
\end{aligned}
$$

in which $f_{\mathrm{yd}}$ and $f_{\mathrm{ys}}$ are the dynamic and quasi-static yield strength; $\dot{\varepsilon}$ is the dynamic strain rate; $\dot{\varepsilon}_{0}$ is the quasi-static strain rate and takes the value of $2.5 \times 10^{-4} / \mathrm{s}_{\mathrm{o}}$.

3.3. Calibration of the Modelling Approach. The validity of the coded subroutine is verified by member tests including quasi-static and dynamic uniaxial loading patterns. The tested columns with the section of $200 \mathrm{~mm} \times 200 \mathrm{~mm}$ and four longitudinal rebars with the diameter of $12 \mathrm{~mm}$ at the corner are tested by the electro-hydraulic servo test system in the structural laboratory of Dalian University of Technology. Specimen construction, reinforcement, and loading are shown in Figure 3, and the test system and loading device are shown in Figure 4.

The parameters of specimens are shown in Table 1. There are a total of six specimens: three specimens S1, S2, and S3 for the quasi-static test and the rest for the dynamic test. The tested specimens are divided into 3 groups as shown in Table 1 . The displacement controlled loading, with loading

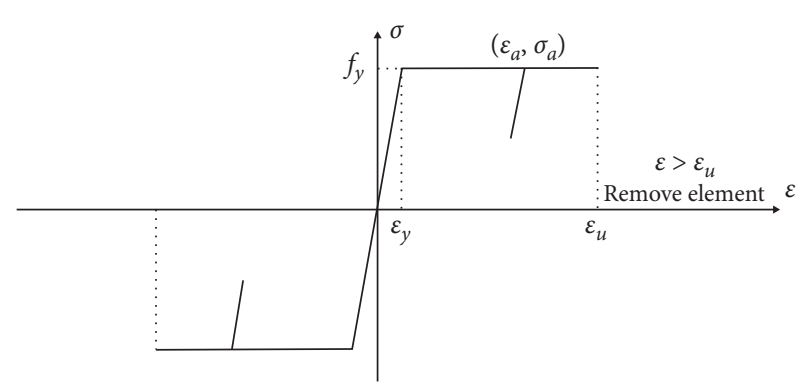

FIGURE 2: Stress-strain curve of rebar.

rates of $0.2 \mathrm{~mm} / \mathrm{s}$ and $40 \mathrm{~mm} / \mathrm{s}$, respectively, was adopted. The loading pattern with a loading rate of $0.2 \mathrm{~mm} / \mathrm{s}$ is regarded as the quasi-static test. The other is regarded as the dynamic test. The loading patterns are shown in Figure 5.

The dynamic explicit method and coded three-dimensional fiber beam-column element model are adopted to investigate the mechanical properties of the tested columns for the numerical analysis. Each tested column is divided into 10 elements, and the integration time step is $0.01 \mathrm{~s}$. The experimental and simulated results are shown in Figure 6.

The results show that the relationship between top displacement and reaction force in the elastic phase looks the same. While the column enters into the plastic stage, the loading rate effect is obvious. It is obvious that the loadbearing capability of column under dynamic loading is bigger than that obtained from the quasi-static test. It also can be seen that the simulated results are in good agreement with experimental data. It can be concluded that the constitutive relationship adopted and coded subroutine are reliable for the plastic analysis of the RC frame structure.

\section{Progressive Collapse of a Four-Story RC Frame Structure}

4.1. Description of the Selected Structure. The progressive collapse analysis of a four-story RC frame is conducted to research the effect of the strain rate on the progressive collapse. The selected structure has a height of $15 \mathrm{~m}$ from the ground and a base dimension of $14.4 \mathrm{~m} \times 16.8 \mathrm{~m}$. The threedimensional finite element model of the structure is shown in Figure 7, and its dimensions and bar arrangement are shown in Figure 8. The contribution of infill walls to the seismic performance of buildings can be apparent [33]. Sometimes, the weight and stiffness of infill walls are unneglectable to the response under earthquake. Furtado et al. [34] developed a simplified macromodel to account for the out-of-plane behaviors of the infill masonry walls. Only the weight of infill walls is considered by adjusting the density of concrete in this paper.

The preceding two mode shapes and periods are calculated through modal analysis. The first mode is the translation mode along the $X$ direction with a period of $0.78 \mathrm{~s}$. The second mode is the translation mode along the $Y$ direction with a period of $0.75 \mathrm{~s}$. The three-dimensional beam element type B31 is employed to model the beam and column. The dimensions of an element for the beam and 


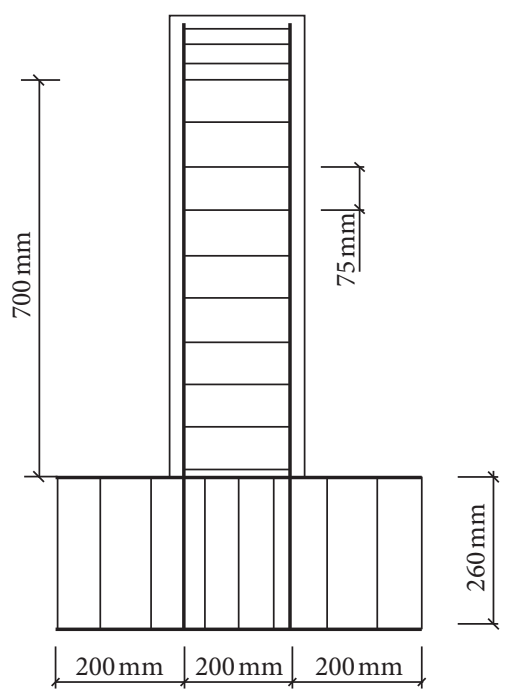

(a)
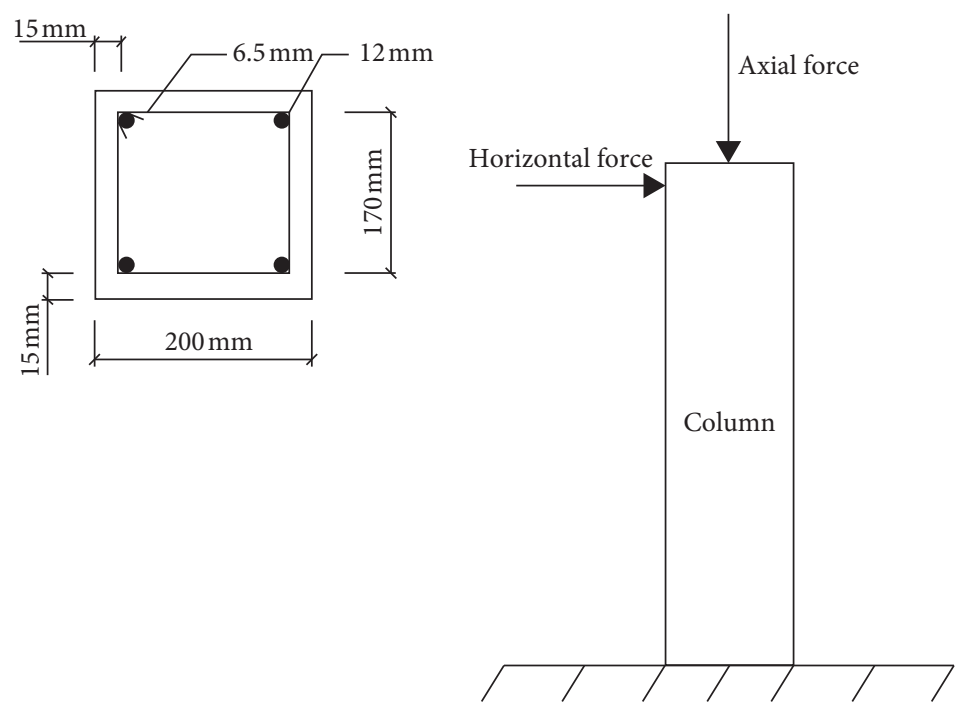

(c)

Figure 3: Specimen construction, reinforcement, and loading. (a) Dimensions. (b) Bar arrangement. (c) Loading.

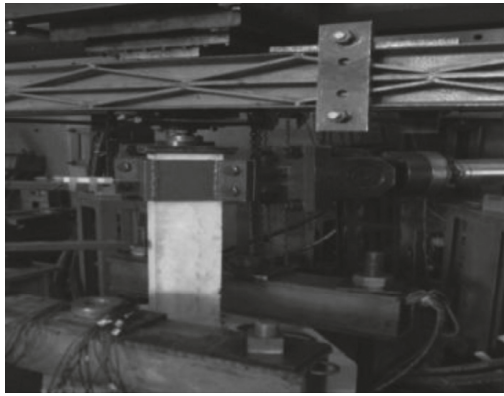

(a)

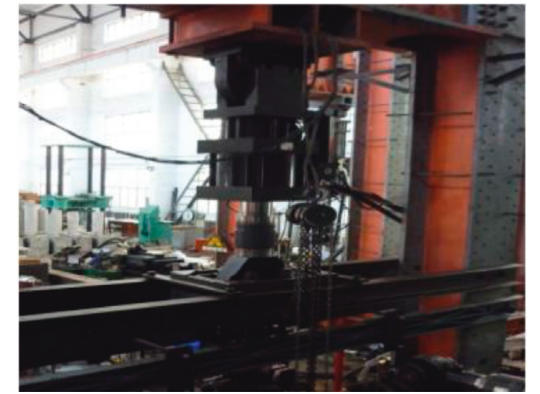

(b)

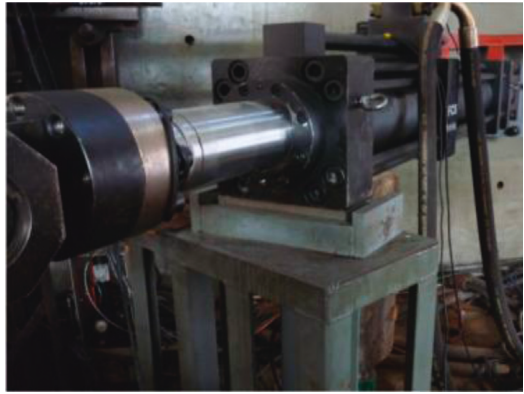

(c)

Figure 4: Test system and loading device. (a) Test setup overview. (b) Axial force loading device. (c) Horizontal force loading device.

TABle 1: Parameters of specimens.

\begin{tabular}{lccc}
\hline Specimen number & S1/D1 & S2/D2 & S3/D3 \\
\hline Axial compression ratio & 0.05 & 0.075 & 0.05 \\
$f_{\text {cu,k }}$ & $50.73 \mathrm{MPa}$ & $50.73 \mathrm{MPa}$ & $71.36 \mathrm{MPa}$ \\
$f_{y}$ & $381.5 \mathrm{MPa}$ & $381.5 \mathrm{MPa}$ & $381.5 \mathrm{MPa}$ \\
\hline
\end{tabular}
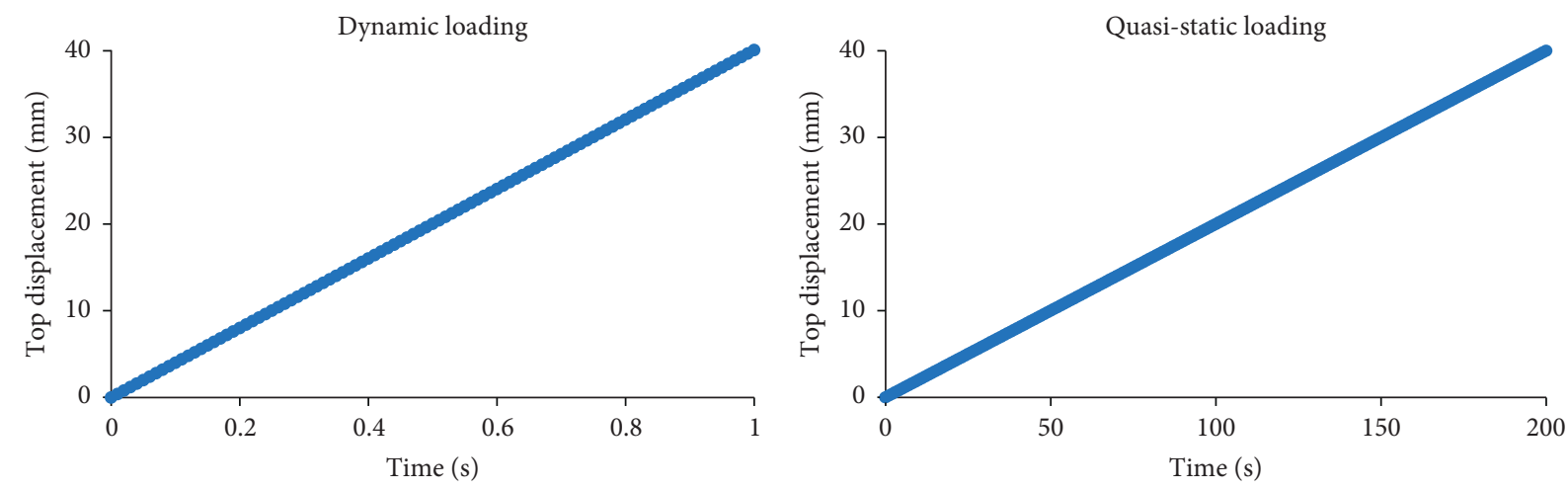

FIGURE 5: Loading patterns. 

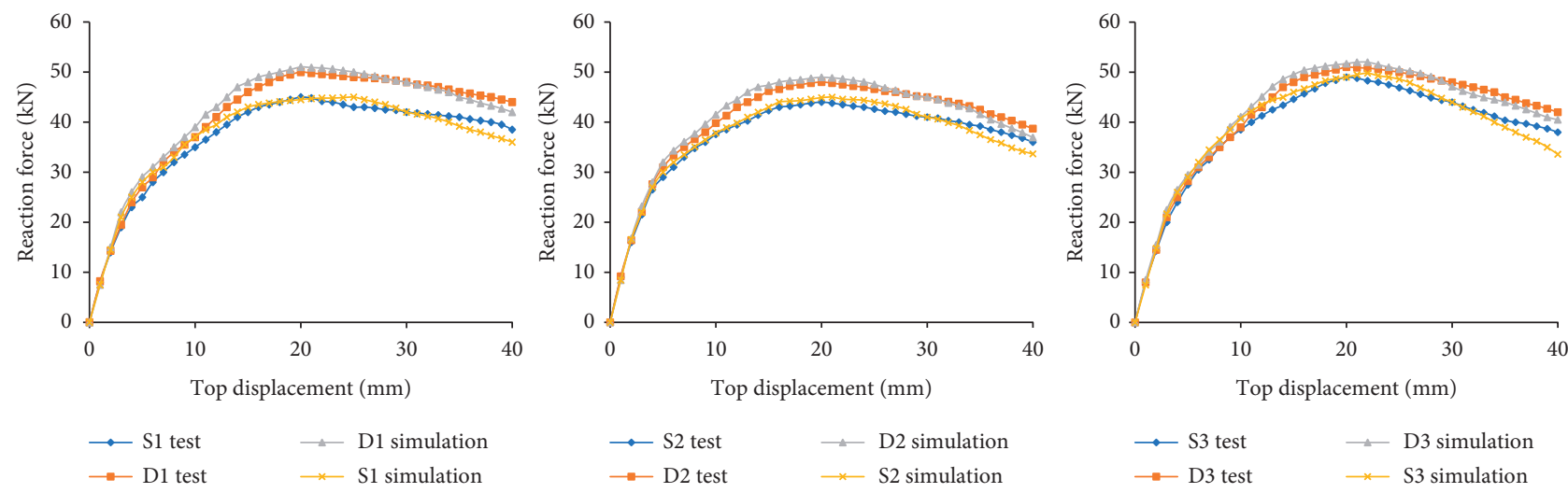

$\begin{array}{ll}\longrightarrow \mathrm{S} 2 \text { test } & \rightarrow \mathrm{D} 2 \text { simulation } \\ \longrightarrow \mathrm{D} 2 \text { test } & \rightarrow \mathrm{S} 2 \text { simulation }\end{array}$

$\longrightarrow \mathrm{S} 3$ test
$\longrightarrow \mathrm{D} 3$ test

D3 simulation

FIgURE 6: Comparison of simulated and test results.

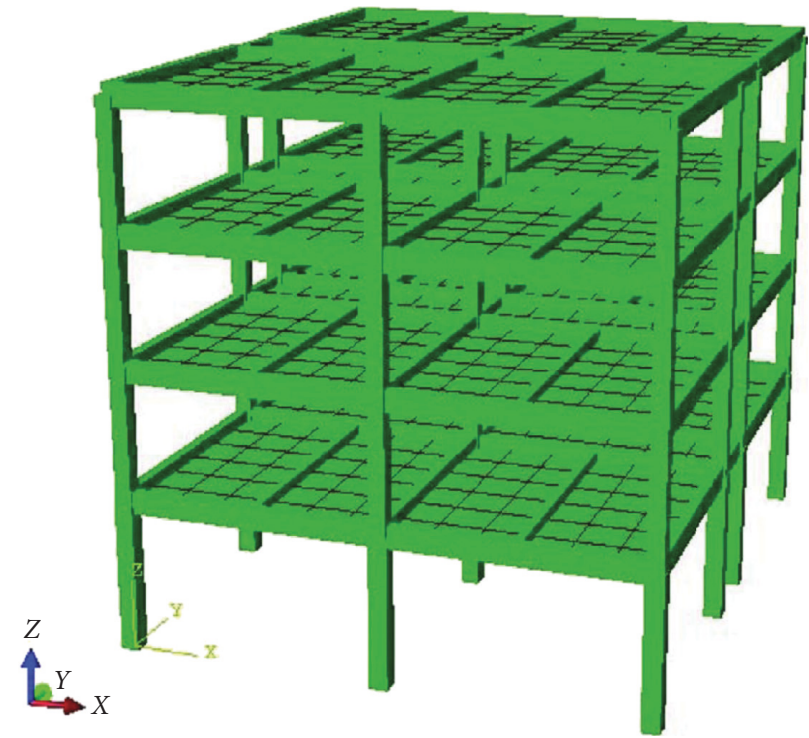

Figure 7: Three-dimensional finite element model.
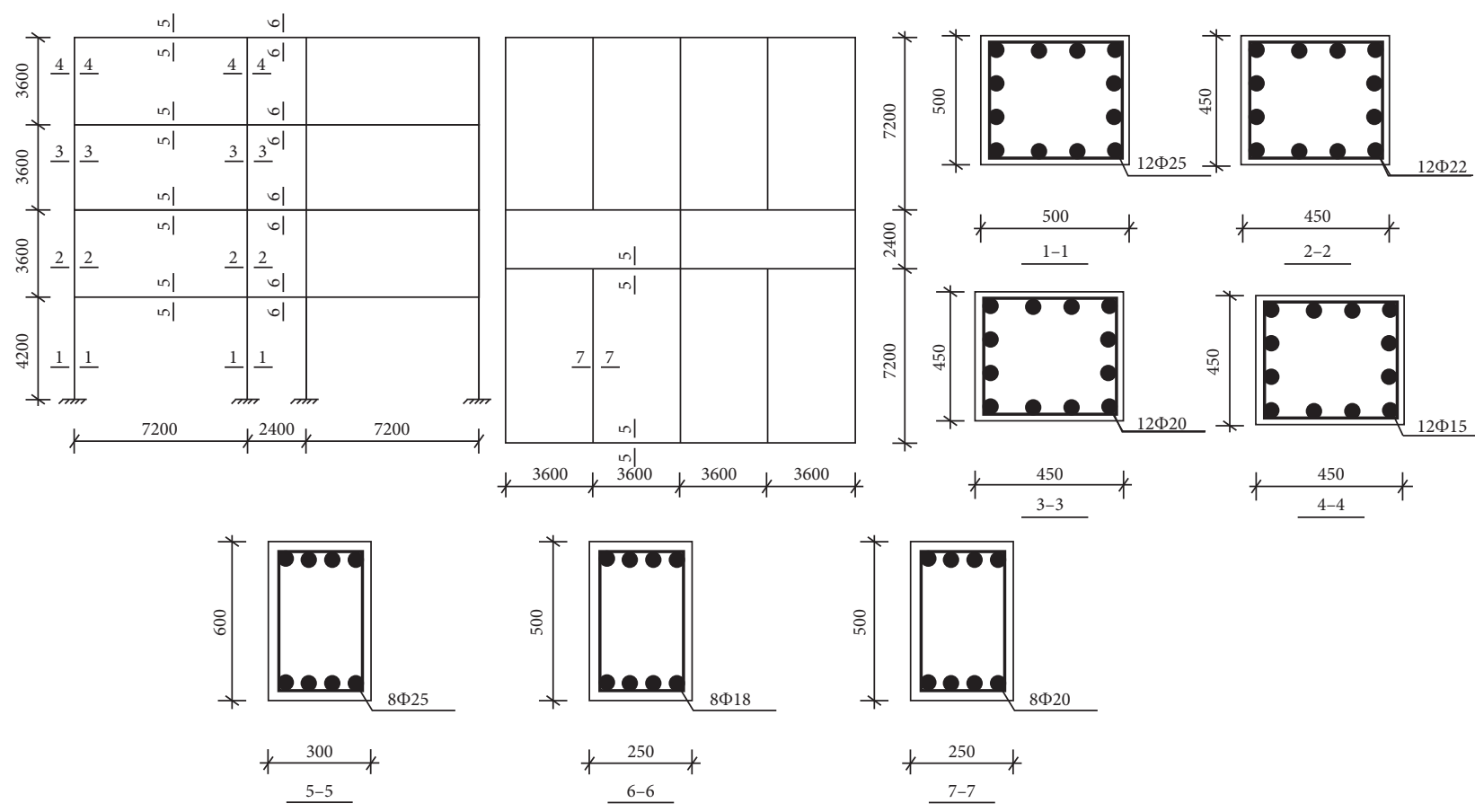

Figure 8: Dimensions and bar arrangement (unit: $\mathrm{mm}$ ). 
column are $1.2 \mathrm{~m}$ and $0.6 \mathrm{~m}$, respectively. The three-dimensional shell element type S4R is applied to model the slab. The dimension of an element for the slab is $1.2 \mathrm{~m} \times 1.2 \mathrm{~m}$. The materials for the rebar and concrete are HRB335 and C30, whose mechanical properties are shown in Tables 2 and 3. The coded subroutine is used for the beam and column in the analysis.

\subsection{Effect of Strain Rate on Collapse-Resistant Capability}

4.2.1. Unidirectional Excitation. The El Centro wave (1940), Taft wave (1952), and Tianjin wave (1976), with the predominant periods of $0.544 \mathrm{~s}, 0.536 \mathrm{~s}$, and $0.970 \mathrm{~s}$, respectively, are selected to study the strain rate effect on the collapse-resistant capacity of the RC frame structure. Unidirectional excitation, along $X$ and $Y$ directions, respectively, is adopted in this section. The incremental dynamic analysis with the coded subroutine is used to assess the structural response. With selected waves, the peak acceleration is modulated to $1.0 \mathrm{~m} / \mathrm{s}^{2}$ first and increased $0.5 \mathrm{~m} / \mathrm{s}^{2}$ each time until the collapse of the structure. It can be seen from the result that the failure process of each member, from yielding to losing the load-bearing capacity, the collapse mode and vulnerable point of the structure can be known. The collapse-resistant capacity of the RC structure subjected to unidirectional excitation is shown in Table 4.

Table 4 shows that the collapse-resistant capacity of the selected structure is not the same under different earthquake excitation due to different characteristics of wave frequency. When the wave is inputted along the $X$ direction, the collapse-resistant capacity is between $3.0 \mathrm{~m} / \mathrm{s}^{2}$ and $7.0 \mathrm{~m} / \mathrm{s}^{2}$. If the wave is inputted along the $Y$ direction, this value is between $3.0 \mathrm{~m} / \mathrm{s}^{2}$ and $7.5 \mathrm{~m} / \mathrm{s}^{2}$. It is also known that the strain rate effect has an obvious influence on the collapseresistant capacity of the structure. After considering the strain rate effect of material, collapse-resistant capacity of the structure rises from $0.5 \mathrm{~m} / \mathrm{s}^{2}$ to $1 \mathrm{~m} / \mathrm{s}^{2}$.

4.2.2. Three-Component Directional Excitation. The El Centro wave (1940), Taft wave (1952), and Tianjin wave (1976), with two horizontal components and one vertical component, are selected to research the strain rate effect on the collapse-resistant capability of the RC frame structure under three-component directional excitation. The vertical and the stronger horizontal components are inputted along $z$ and $y$ directions and another is inputted along the $\mathrm{x}$ direction. With the selected earthquake waves, the peak acceleration of the stronger component is modulated to $1 \mathrm{~m} / \mathrm{s}^{2}$, and the other two components are modulated according to the ratio of their peak acceleration. Then, the peak acceleration of the stronger component is increased $0.5 \mathrm{~m} / \mathrm{s}^{2}$ each time until the collapse of the structure. The collapse-resistant capacity of the RC structure subjected to three-component directional excitation is shown in Table 5. It shows that the collapse-resistant capacity of the selected structure is not the same under different earthquake excitation due to their different frequency characteristics. Under Tianjin wave, the structure is easier to collapse than under other earthquake
TABLE 2: Mechanical properties of HRB335.

\begin{tabular}{ccccc}
\hline Material & $f_{y}(\mathrm{~Pa})$ & $E_{s}(\mathrm{~Pa})$ & Density $\left(\mathrm{kg} / \mathrm{m}^{3}\right)$ & $\varepsilon_{u}$ \\
\hline HRB335 & $3.35 E+8$ & $2.00 E+11$ & 7850 & 0.067 \\
\hline
\end{tabular}

TABLE 3: Mechanical properties of C30.

\begin{tabular}{lcccccc}
\hline Material & $f_{c}^{*}(\mathrm{~Pa})$ & $f_{t}^{*}(\mathrm{~Pa})$ & $E_{c}(\mathrm{~Pa})$ & $\begin{array}{c}\text { Density } \\
\left(\mathrm{kg} / \mathrm{m}^{3}\right)\end{array}$ & $\varepsilon_{f}$ & $\varepsilon_{\mathrm{cu}}$ \\
\hline $\mathrm{C} 30$ & $2.0 E+7$ & $2.0 E+6$ & $3.00 E+10$ & 2500 & 0.0004 & 0.0033 \\
\hline
\end{tabular}

waves. It is also known that the strain rate effect has an obvious influence on the collapse-resistant capacity of the structure under three-component directional excitation. After considering the strain rate effect, collapse-resistant capacity of the RC structure increases $0.5 \mathrm{~m} / \mathrm{s}^{2}$. By comparing Table 4 with Table 5 , it shows that the structure is easier to collapse under three-component directional excitation than under unidirectional excitation.

\subsection{Effect of Strain Rate on Collapse Process}

4.3.1. Collapse Process without considering Strain Rate Effect. Three-component directional excitation is adopted to study the strain rate effect on the progressive collapse process of the RC frame structure. Figure 9 shows the collapse process of the structure under El Centro wave with a peak acceleration of $4.5 \mathrm{~m} / \mathrm{s}^{2}$. At $t=1.99 \mathrm{~s}$, an element of column at the second story yielded first. And then, at $t=6.55 \mathrm{~s}$, the element yielded first lost the load-bearing capacity.

Figure 10 shows the collapse process of the structure under Taft wave with a peak acceleration of $4.0 \mathrm{~m} / \mathrm{s}^{2}$. At $t=3.51 \mathrm{~s}$, an element of column at the second story yielded first. And then, at $t=9.28 \mathrm{~s}$, the element yielded first lost the load-bearing capacity.

Figure 11 shows the collapse process of the structure under Tianjin wave with a peak acceleration of $2.5 \mathrm{~m} / \mathrm{s}^{2}$. At $t=6.51 \mathrm{~s}$, an element of column at the second story yielded first. And then, at $t=13.28 \mathrm{~s}$, the element yielded first lost the load-bearing capacity. It can be seen from Figures 9-11 that the collapse process begins from the losing load-bearing capacity of the column at the second story and this story collapsed first. Therefore, the second story is the weak floor.

4.3.2. Collapse Process considering Strain Rate Effect. In this section, the strain rate effect is added to study the progressive collapse process of the RC frame structure. Figures 12-14 show the collapse process of the structure under El Centro wave, Taft wave, and Tianjin wave, with peak accelerations of $5.0 \mathrm{~m} / \mathrm{s}^{2}, \quad 4.5 \mathrm{~m} / \mathrm{s}^{2}$, and $3.0 \mathrm{~m} / \mathrm{s}^{2}$, respectively. Under $\mathrm{El}$ Centro wave, a column at the first floor lost the load-bearing capacity during the collapse process. It is obviously different from the collapse process without considering the strain rate effect. Under Taft wave, the structure collapsed from the second floor also. When the strain rate effect is not included, the left part of the slab in floor 2 collides with the slab of the first floor. If the strain rate effect is added, the collapse 
TABLE 4: Collapse-resistant capacity of the RC structure subjected to unidirectional excitation.

\begin{tabular}{|c|c|c|c|c|}
\hline \multirow{2}{*}{$\begin{array}{l}\text { Earthquake } \\
\text { wave }\end{array}$} & \multicolumn{2}{|c|}{ Input along $X$ direction } & \multicolumn{2}{|c|}{ Input along $Y$ direction } \\
\hline & $\begin{array}{c}\text { Considering strain rate } \\
\text { effect }\end{array}$ & $\begin{array}{c}\text { Without considering strain rate } \\
\text { effect }\end{array}$ & $\begin{array}{c}\text { Considering strain rate } \\
\text { effect }\end{array}$ & $\begin{array}{c}\text { Without considering strain rate } \\
\text { effect }\end{array}$ \\
\hline $\begin{array}{l}\text { El Centro } \\
(1940)\end{array}$ & $8.0 \mathrm{~m} / \mathrm{s}^{2}$ & $7.0 \mathrm{~m} / \mathrm{s}^{2}$ & $8.5 \mathrm{~m} / \mathrm{s}^{2}$ & $7.5 \mathrm{~m} / \mathrm{s}^{2}$ \\
\hline Taft (1952) & $6.5 \mathrm{~m} / \mathrm{s}^{2}$ & $5.5 \mathrm{~m} / \mathrm{s}^{2}$ & $6.5 \mathrm{~m} / \mathrm{s}^{2}$ & $5.5 \mathrm{~m} / \mathrm{s}^{2}$ \\
\hline Tianjin (1976) & $3.5 \mathrm{~m} / \mathrm{s}^{2}$ & $3.0 \mathrm{~m} / \mathrm{s}^{2}$ & $3.5 \mathrm{~m} / \mathrm{s}^{2}$ & $3.0 \mathrm{~m} / \mathrm{s}^{2}$ \\
\hline
\end{tabular}

TABLE 5: Collapse-resistant capability of the RC structure subjected to three-component directional excitation.

\begin{tabular}{lcc}
\hline Earthquake wave & Considering strain rate effect & Without considering strain rate effect \\
\hline El Centro (1940) & $5.0 \mathrm{~m} / \mathrm{s}^{2}$ & $4.5 \mathrm{~m} / \mathrm{s}^{2}$ \\
Taft (1952) & $4.5 \mathrm{~m} / \mathrm{s}^{2}$ & $4.0 \mathrm{~m} / \mathrm{s}^{2}$ \\
Tianjin (1976) & $3.0 \mathrm{~m} / \mathrm{s}^{2}$ & $2.5 \mathrm{~m} / \mathrm{s}^{2}$ \\
\hline
\end{tabular}

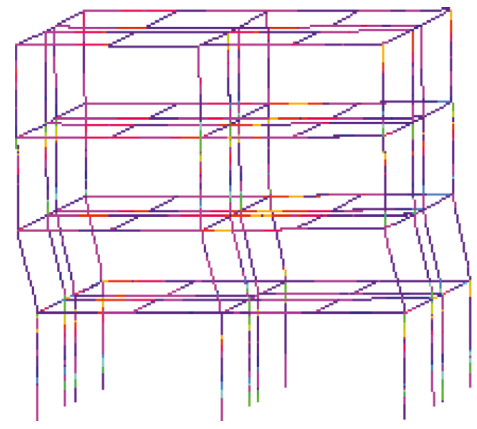

(a)

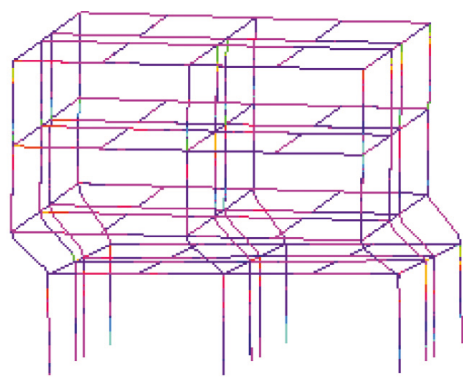

(d)

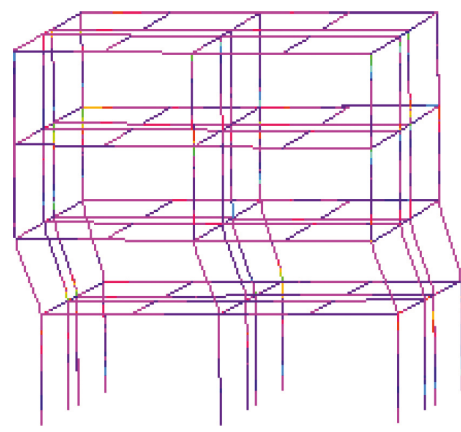

(b)

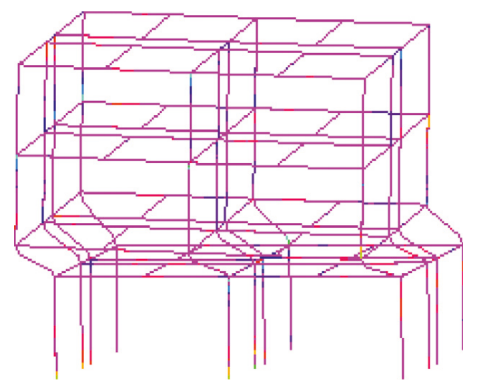

(e)

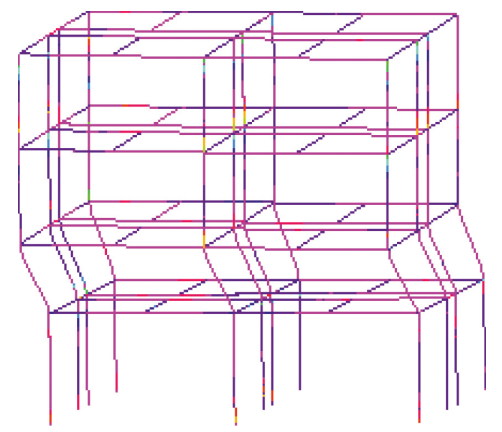

(c)

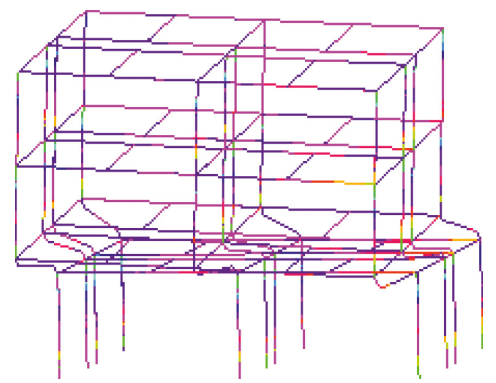

(f)

Figure 9: Collapse process of the structure subjected to three-component excitation under El Centro wave. (a) $t=9.50 \mathrm{~s}$. (b) $t=9.70 \mathrm{~s}$. (c) $t=9.80 \mathrm{~s}$. (d) $t=10.0 \mathrm{~s}$. (e) $t=10.2 \mathrm{~s}$. (f) $t=10.5 \mathrm{~s}$.

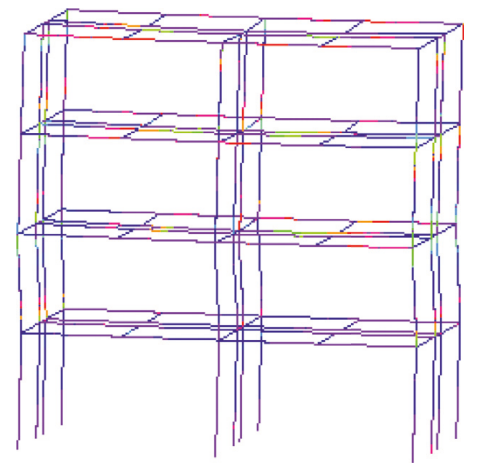

(a)

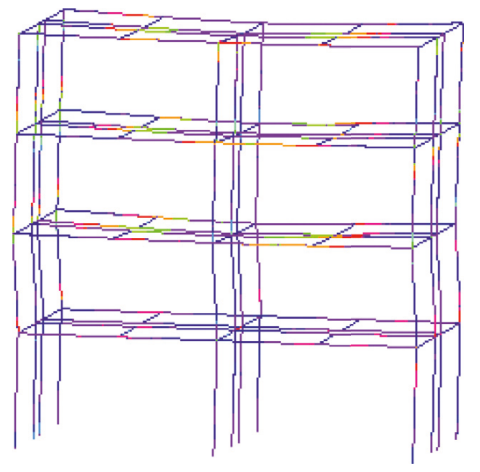

(b)

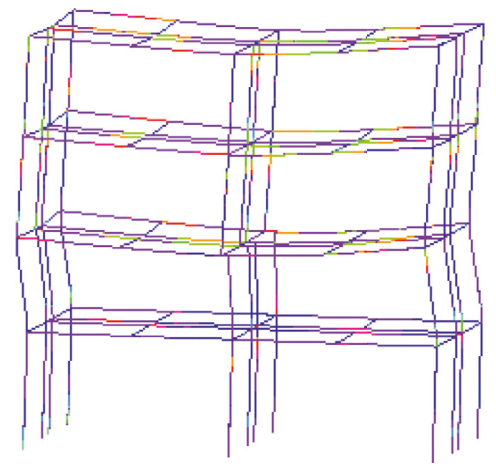

(c)

Figure 10: Continued. 


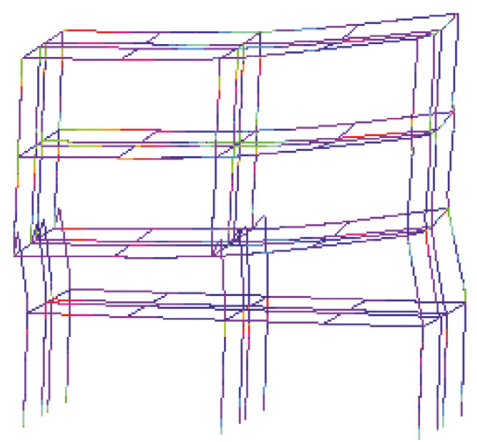

(d)

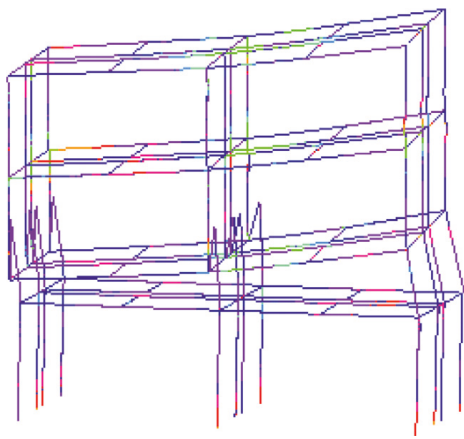

(e)

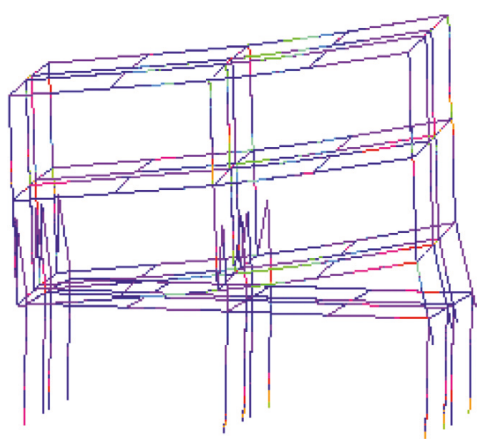

(f)

Figure 10: Collapse process of the structure subjected to three-component excitation under Taft wave. (a) $t=9.0 \mathrm{~s}$. (b) $t=9.5 \mathrm{~s}$. (c) $t=10.0 \mathrm{~s}$. (d) $t=10.3 \mathrm{~s}$. (e) $t=10.5 \mathrm{~s}$. (f) $t=10.7 \mathrm{~s}$.

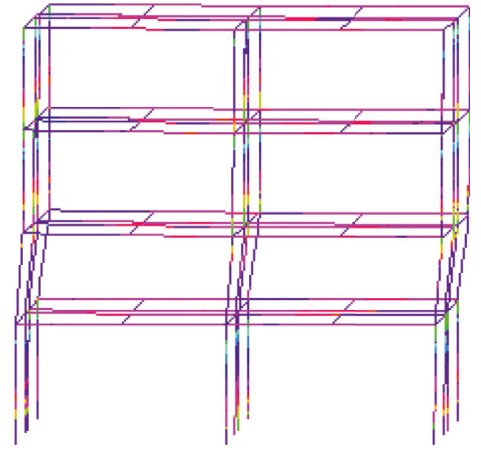

(a)

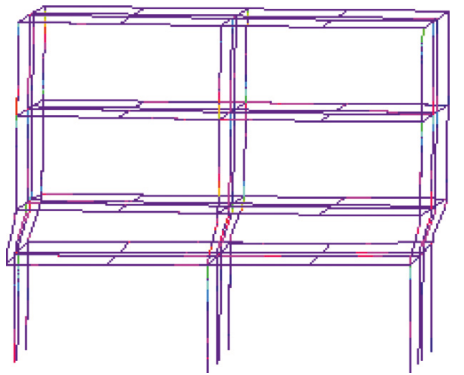

(d)

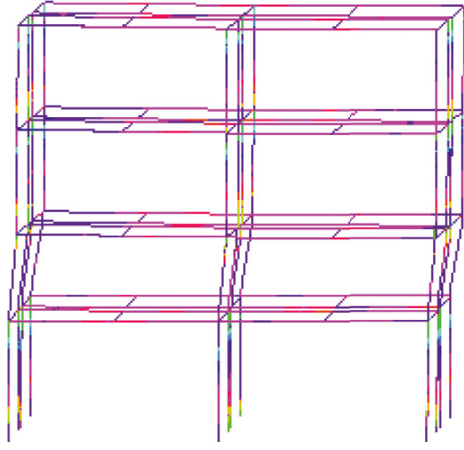

(b)

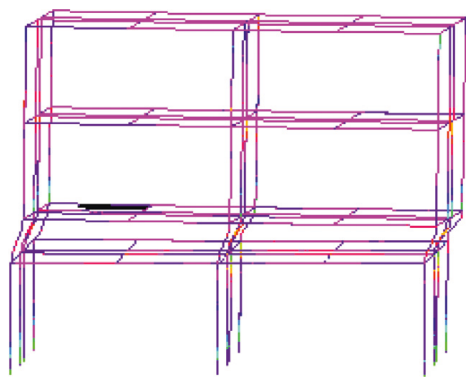

(e)

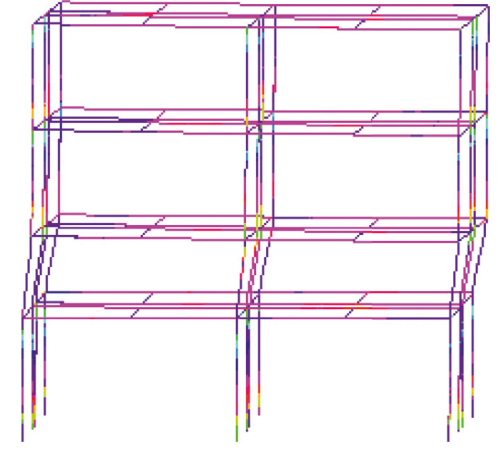

(c)

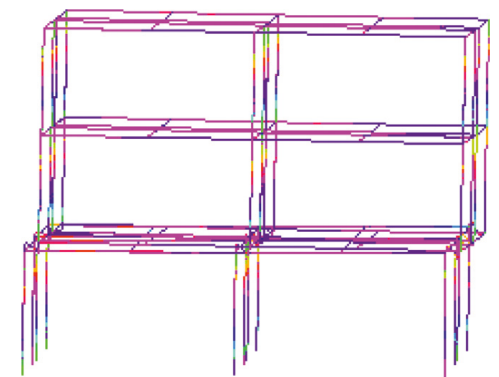

(f)

FIGURE 11: Collapse process of the structure subjected to three-component excitation under Tianjin wave. (a) $t=13.4 \mathrm{~s}$. (b) $t=13.5 \mathrm{~s}$. (c) $t=13.6 \mathrm{~s}$. (d) $t=13.8 \mathrm{~s}$. (e) $t=13.9 \mathrm{~s}$. (f) $t=14.1 \mathrm{~s}$.

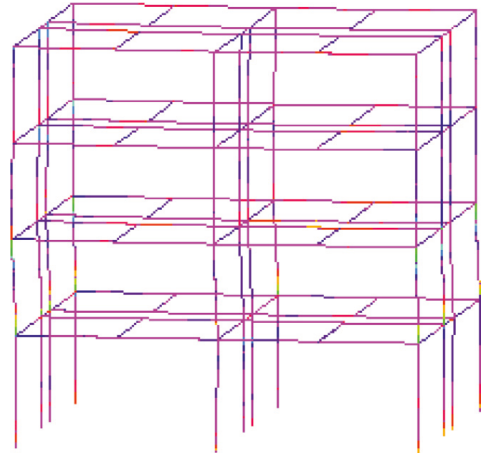

(a)

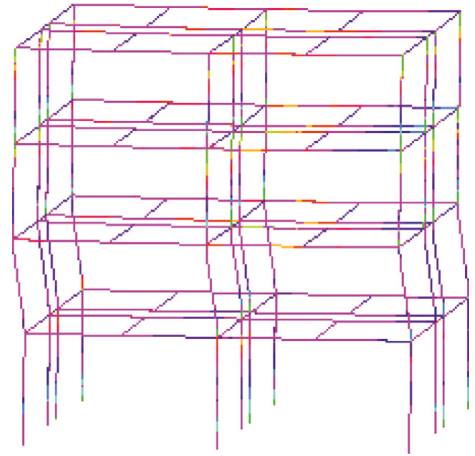

(b)

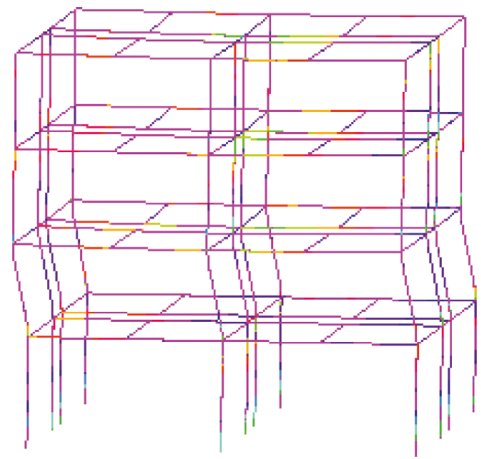

(c)

FIgURE 12: Continued. 


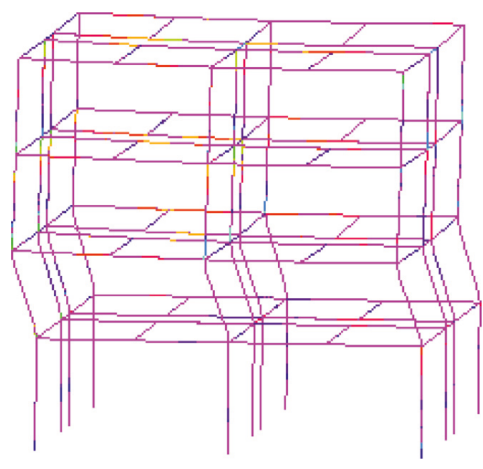

(d)

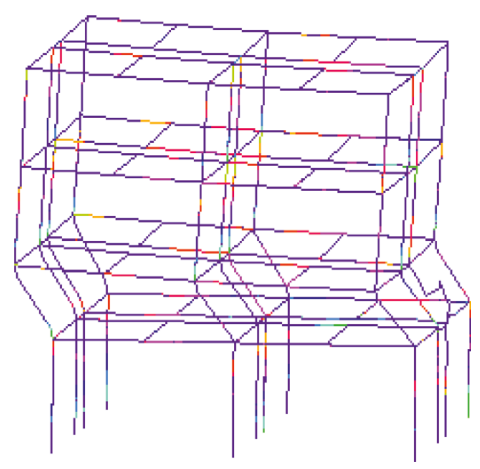

(e)

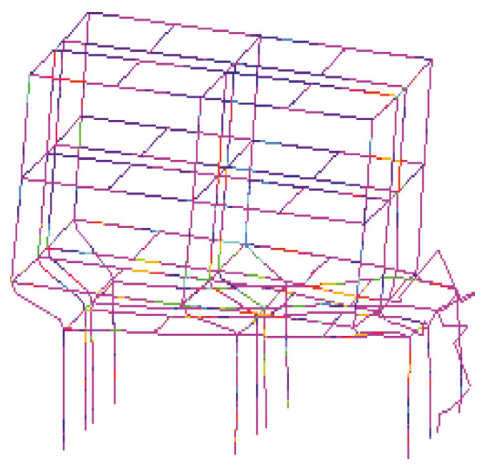

(f)

FIGURE 12: Collapse process of the structure subjected to three-component excitation under El Centro wave considering strain rate effect. (a) $t=11.0 \mathrm{~s}$. (b) $t=12.0 \mathrm{~s}$. (c) $t=12.2 \mathrm{~s}$. (d) $t=12.5 \mathrm{~s}$. (e) $t=12.8 \mathrm{~s}$. (f) $t=13.0 \mathrm{~s}$.

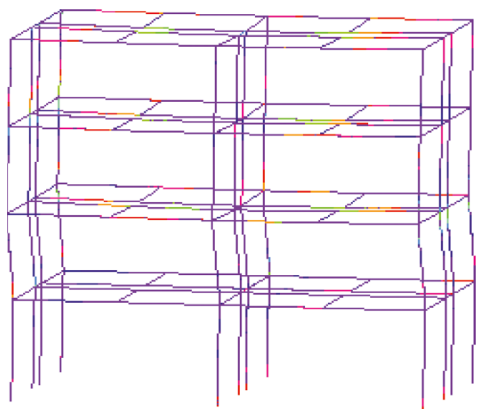

(a)

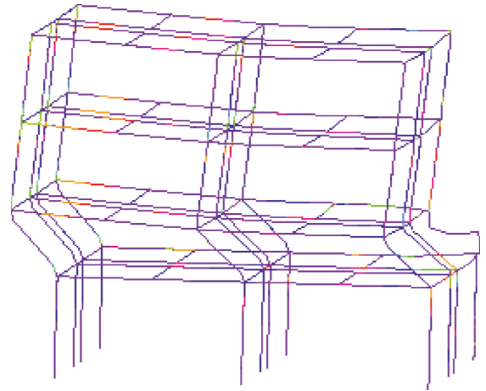

(d)

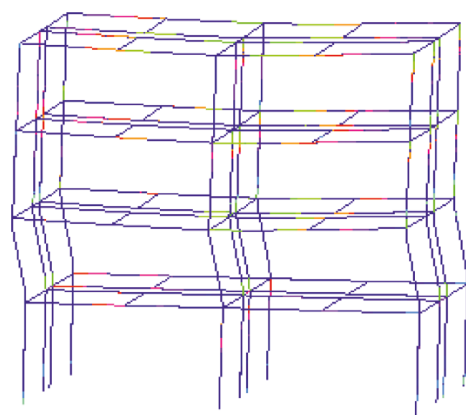

(b)

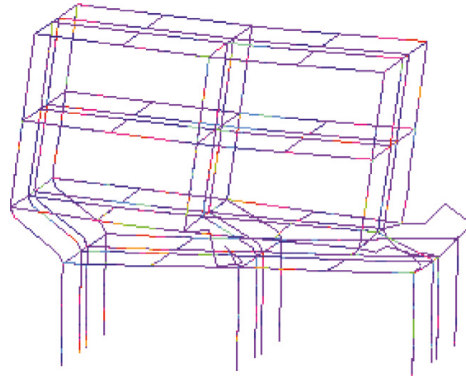

(e)

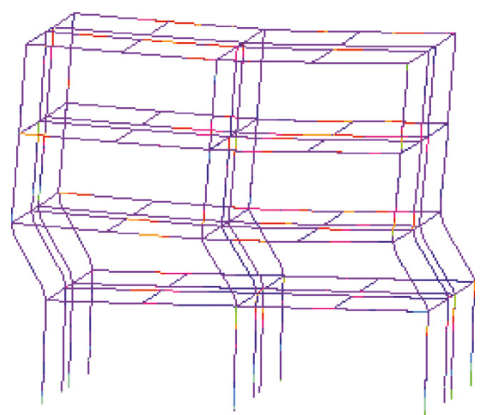

(c)

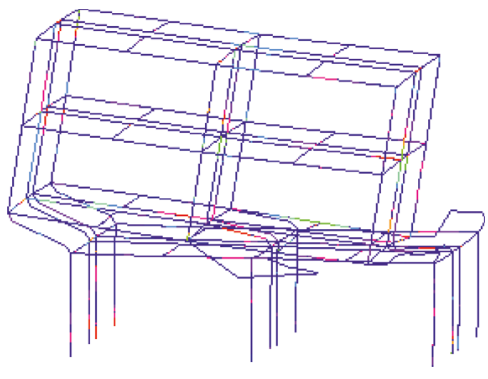

(f)

FIGURE 13: Collapse process of the structure subjected to three-component excitation under Taft wave considering strain rate effect. (a) $t=12.0 \mathrm{~s}$. (b) $t=13.0 \mathrm{~s}$. (c) $t=13.5 \mathrm{~s}$. (d) $t=13.7 \mathrm{~s}$. (e) $t=13.8 \mathrm{~s}$. (f) $t=14.0 \mathrm{~s}$.

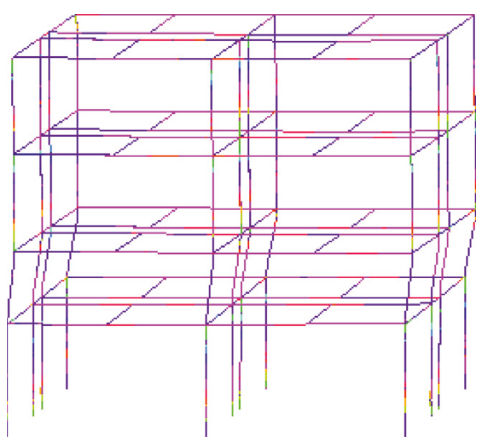

(a)

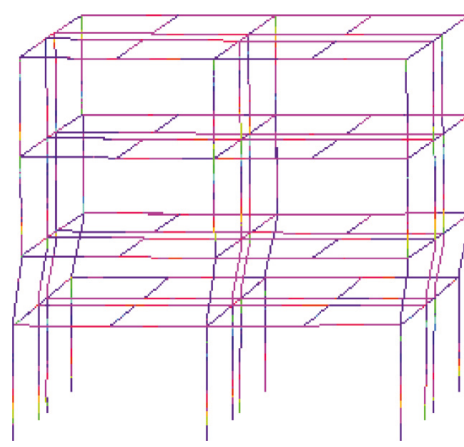

(b)

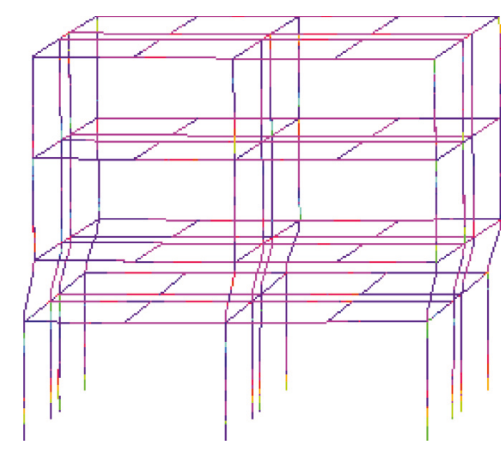

(c)

Figure 14: Continued. 


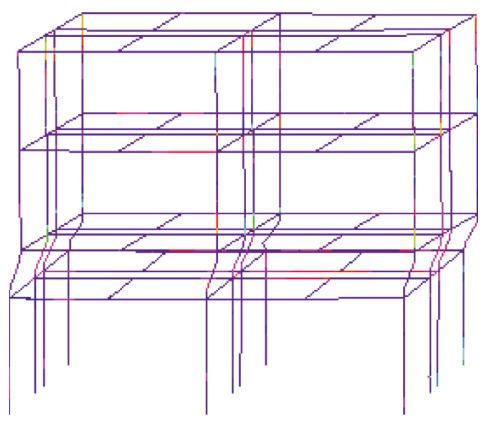

(d)

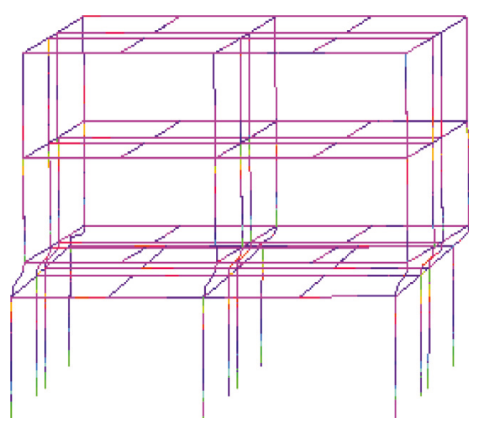

(e)

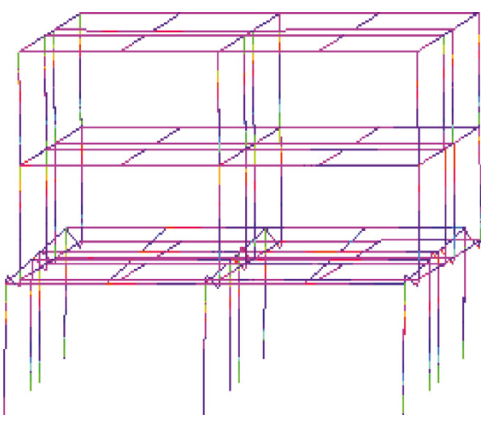

(f)

FIGURE 14: Collapse process of the structure subjected to three-component excitation under Tianjin wave considering strain rate effect. (a) $t=13.1$ s. (b) $t=13.2 \mathrm{~s}$. (c) $t=13.3 \mathrm{~s}$. (d) $t=13.4 \mathrm{~s}$. (e) $t=13.5 \mathrm{~s}$. (f) $t=13.7 \mathrm{~s}$.

TABLE 6: Response summary of the structure subjected to three-component directional excitation.

\begin{tabular}{|c|c|c|c|c|c|c|}
\hline \multirow{2}{*}{$\begin{array}{l}\text { Earthquake } \\
\text { wave }\end{array}$} & \multicolumn{3}{|c|}{ Rate-dependent model } & \multicolumn{3}{|c|}{ Rate-independent model } \\
\hline & $\begin{array}{l}\text { Location of the } \\
\text { failure element }\end{array}$ & $\begin{array}{l}\text { Time of the } \\
\text { failure }\end{array}$ & $\begin{array}{l}\text { Corresponding } \\
\text { acceleration }\end{array}$ & $\begin{array}{l}\text { Location of the } \\
\text { failure element }\end{array}$ & $\begin{array}{l}\text { Time of the } \\
\text { failure }\end{array}$ & $\begin{array}{c}\text { Corresponding } \\
\text { acceleration }\end{array}$ \\
\hline El Centro (1940) & $\begin{array}{l}\text { A column at the } \\
\text { first story }\end{array}$ & $8.78 \mathrm{~s}$ & $5.0 \mathrm{~m} / \mathrm{s}^{2}$ & $\begin{array}{l}\text { A column at the } \\
\text { second story }\end{array}$ & $6.55 \mathrm{~s}$ & $4.5 \mathrm{~m} / \mathrm{s}^{2}$ \\
\hline Taft (1952) & $\begin{array}{l}\text { A column at the } \\
\text { second story }\end{array}$ & $12.37 \mathrm{~s}$ & $4.5 \mathrm{~m} / \mathrm{s}^{2}$ & $\begin{array}{l}\text { A column at the } \\
\text { second story }\end{array}$ & $9.28 \mathrm{~s}$ & $4.0 \mathrm{~m} / \mathrm{s}^{2}$ \\
\hline Tianjin (1976) & $\begin{array}{l}\text { A column at the second } \\
\text { story }\end{array}$ & $13.10 \mathrm{~s}$ & $3.0 \mathrm{~m} / \mathrm{s}^{2}$ & $\begin{array}{l}\text { A column at the } \\
\text { second story }\end{array}$ & $13.28 \mathrm{~s}$ & $2.5 \mathrm{~m} / \mathrm{s}^{2}$ \\
\hline
\end{tabular}

process changes obviously. It is the right part of the slab in floor 2 collides with that of the first floor. There is no obvious difference on the collapse mode under the Tianjin wave. It can be seen from the above analysis that the collapse mode of the $\mathrm{RC}$ frame structure is relative to the strain rate effect. Therefore, the strain rate effect should be considered for the progressive collapse analysis of the RC frame structure to obtain the reliable collapse mode, collapse path, collapseresistant capacity, and so on.

\section{Summaries and Conclusions}

According to the "Code for Design of Concrete Structures" (GB 50010-2010) in China, the progressive collapse simulation program is coded using the user subroutine VUMAT and then implemented in the finite element program ABAQUS. With the coded user subroutine, the strain rate effect of concrete and rebar can be included in the constitutive relationship. By conducting progressive collapse analyses of a four-story RC frame structure under earthquake, the effect of strain rate on collapse-resistant capacity, collapse mode, and collapse path is investigated. The response summary of the structure subjected to three-component directional excitation is shown in Table 6. The main conclusions are as follows:

(1) There is apparent difference on the mechanical properties of RC columns between dynamic and quasi-static loading as validated by the experimental data of test specimens. Therefore, the strain rate effect should be considered for the seismic analysis of RC members.
(2) The strain rate effect has an obvious influence on the collapse-resistant capacity of the RC frame structure under both unidirectional excitation and threecomponent directional excitation. After considering the strain rate effect, collapse-resistant capacity of the RC structure increases from $0.5 \mathrm{~m} / \mathrm{s}^{2}$ to $1 \mathrm{~m} / \mathrm{s}^{2}$.

(3) The influence of the strain rate effect on the collapse mode and collapse path of the RC frame structure cannot be neglected. In some cases, the collapse mode and collapse path change obviously after the strain rate effect is included.

(4) More investigations are needed to investigate the strain rate effect on the seismic response of shear wall structures and other types of RC structures, especially for high-rise buildings.

\section{Data Availability}

The numerical data used to support the findings of this study are available from the corresponding author upon request.

\section{Conflicts of Interest}

The author declares that there are no conflicts of interest regarding the publication of this article.

\section{Acknowledgments}

This research work was jointly supported by the National Natural Science Foundation of China (Grant nos. 2016YFC0701108, 51908340, and 51808092). 


\section{References}

[1] D. A. Abrams, "Effect of rate of application of load on the compressive strength of concrete," Proceedings of American Society for Testing Materials, vol. 17, pp. 364-377, 1917.

[2] D. Watstein, "Effect of straining rate on the compressive strength and elastic properties of concrete," ACI Journal Proceedings, vol. 49, no. 4, pp. 729-744, 1953.

[3] B. P. Hughes and R. Gregory, "Concrete subjected to high rates of loading in compression," Magazine of Concrete Research, vol. 24, no. 78, pp. 25-36, 1972.

[4] P. H. Bischoff and S. H. Perry, "Compressive behaviour of concrete at high strain rates," Materials and Structures, vol. 24, no. 6, pp. 425-450, 1991.

[5] L. J. Malvar and C. A. Ross, "Review of strain rate effects for concrete in tension," ACI Materials Journal, vol. 95, no. 6, pp. 735-739, 1998.

[6] E. A. Davis, "The effect of speed of stretching and the rate of loading on the yielding of mild steel," Journal of Applied Mechanics, vol. 5, no. 4, pp. 137-140, 1938.

[7] K. C. Chang and G. C. Lee, "Strain rate effect on structural steel under cyclic loading," Journal of Engineering Mechanics, vol. 113, no. 9, pp. 1292-1301, 1987.

[8] J. I. Restrepo-Posada, L. L. Dodd, R. Park, and N. Cooke, "Variables affecting cyclic behavior of reinforcing steel," Journal of Structural Engineering, vol. 120, no. 11, pp. 31783196, 1994.

[9] M. Li and H.-N Li, "Dynamic test and constitutive model for reinforcing steel," China Civil Engineering Journal, vol. 43, no. 4, pp. 70-75, 2008.

[10] D. Asprone, R. Frascadore, M. Di Ludovico, A. Prota, and G. Manfredi, "Influence of strain rate on the seismic response of RC structures," Engineering Structures, vol. 35, pp. 29-36, 2012.

[11] H.-N. Li and M. Li, "Experimental and numerical study on dynamic properties of RC beam," Magazine of Concrete Research, vol. 65, no. 12, pp. 744-756, 2013.

[12] D. Wang, H. Li, and G. Li, "Experimental tests on reinforced concrete columns under multi-dimensional dynamic loadings," Construction and Building Materials, vol. 47, no. 5, pp. 1167-1181, 2013.

[13] H. Zhang, H.-N. Li, C. Li, and G.-W. Cao, "Experimental and numerical investigations on seismic responses of reinforced concrete structures considering strain rate effect," Construction and Building Materials, vol. 173, pp. 672-686, 2018.

[14] ASCE, ASCE 7-05: Minimum Design Loads for Buildings and other Structures, ASCE, Reston, VA, USA, 2005.

[15] P. A. Cundall and O. D. L. Stract, "A discrete numerical model for granular assemblies," Géotechnique, vol. 29, no. 1, pp. 47-65, 1979.

[16] L. Sun, C. Zhou, D. Qin, and L. Fan, "Application of extended distinct element method with lattice model to collapse analysis of RC bridges," Earthquake Engineering \& Structural Dynamics, vol. 32, no. 8, pp. 1217-1236, 2003.

[17] J. Hou, M. Zhou, and Z. Yang, "Simulation on the collapse process of 3-D concrete frame structures considering impact action between concrete blocks," Engineering Mechanics, vol. 27, no. 6, pp. 89-97, 2010.

[18] Q. Huang, Study on Spatial Collapse Responses of Reinforced Concrete Frame Structures under Earthquake, Tongji University, Shanghai, China, 2006.

[19] A. Munjiza, D. R. J. Owen, and N. Bicanic, "A combined finite-discrete element method in transient dynamics of fracturing solids," Engineering Computations, vol. 12, no. 2, pp. 145-174, 1995.

[20] A. Munjiza, T. Bangash, and N. W. M. John, "The combined finite-discrete element method for structural failure and collapse," Engineering Fracture Mechanics, vol. 71, no. 4-6, pp. 469-483, 2004.

[21] K. Meguro and M. Hakuno, "Fracture analysis of concrete structures by the modified distinct element method," Doboku Gakkai Ronbunshu, vol. 1989, no. 410, pp. 113-124, 1989.

[22] K. Meguro and H. Tagel-Din, "Applied element method for structural analysis: theory and application for linear materials," Structural Engineering Earthquake Engineering, vol. 17, no. 1, pp. 21-35, 2000.

[23] K. Meguro and H. Tagel-Din, "Applied element simulation of RC structures under cyclic loading," Journal of Structural Engineering, vol. 127, no. 11, pp. 1295-1305, 2001.

[24] Y. Yu and X. Luo, "Structural collapse analysis based on finite particle method I: basic approach," Journal of Building Structures, vol. 32, no. 11, pp. 17-26, 2011.

[25] Y. Yu and Y. Luo, "Structural collapse analysis based on finite particle method II: key problems and numerical examples," Journal of Building Structures, vol. 32, no. 11, pp. 27-35, 2011.

[26] D. Isobe and M. Tsuda, "Seismic collapse analysis of reinforced concrete framed structures using the finite element method," Earthquake Engineering \& Structural Dynamics, vol. 32, no. 13, pp. 2027-2046, 2003.

[27] X. Lu, X. Lin, L. Ye et al., "Numerical models for earthquake induced progressive collapse of high-rise buildings," Engineering Mechanics, vol. 27, no. 11, pp. 64-70, 2010.

[28] W. M. Wang, H. N. Li, and L. Tian, "Progressive collapse analysis of transmission tower-line system under earthquake," Advanced Steel Construction, vol. 9, no. 2, pp. 161-172, 2013.

[29] ABAQUS Inc, ABAQUS Analysis User's Manual, Vol. III, ABAQUS INC, Palo Alto, CA, USA, 2010.

[30] GB50010-2010, Code for Design of Concrete Structures, Chinese Architecture Industry Press, Beijing, China, 2010.

[31] Y.-L. Dong, H.-P. Xie, and P. Zhao, "Experimental study and constitutive model on concrete under compression with different strain rate," Journal of Hydraulic Engineering, vol. 7, pp. 72-77, 1997.

[32] X. Shi-yun, L. Gao, Z. Wang, and J.-Z. Lu, "Effects of strain on dynamic behavior of concrete in tension," Journal of Dalian University of Technology, vol. 41, no. 6, pp. 721-725, 2001.

[33] H. Varum, R. Dumaru, A. Furtado, A. R. Barbosa, D. Gautam, and H. Rodrigues, "Chapter 3-seismic performance of buildings in Nepal after the Gorkha earthquake," in Impacts and Insights of the Gorkha Earthquake, D. Gautam and H. Rodrigues, Eds., pp. 47-63, Elsevier, Amsterdam, Netherlands, 2018.

[34] A. Furtado, H. Rodrigues, A. Arêde, and H. Varum, "Influence of the in plane and out-of-plane masonry infill walls' interaction in the structural response of RC buildings," Procedia Engineering, vol. 114, pp. 722-729, 2015. 


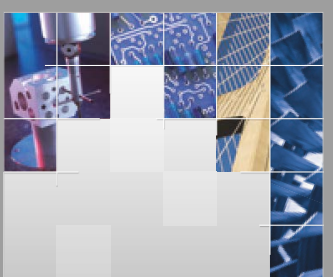

\section{Enfincering}
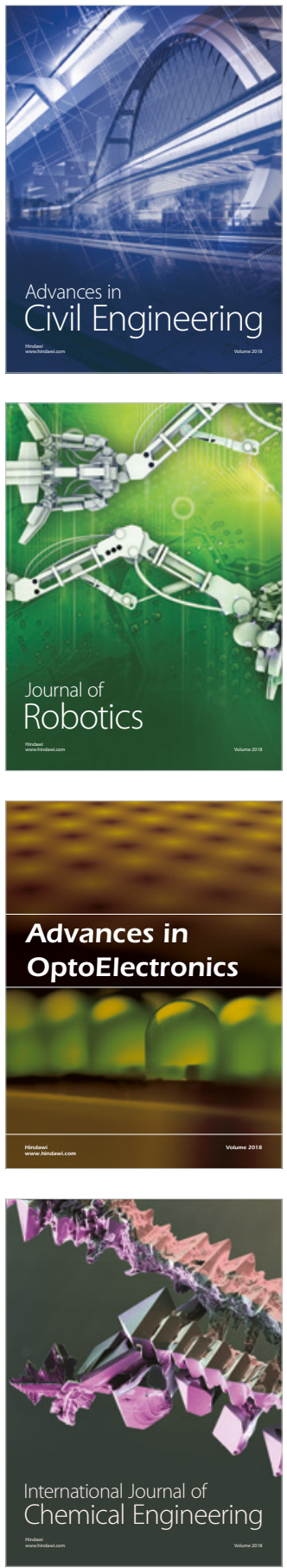

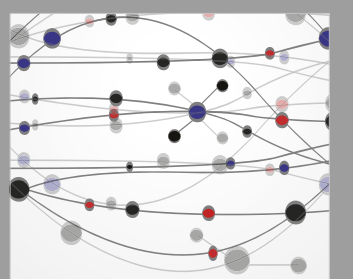

\section{Rotating \\ Machinery}

The Scientific World Journal

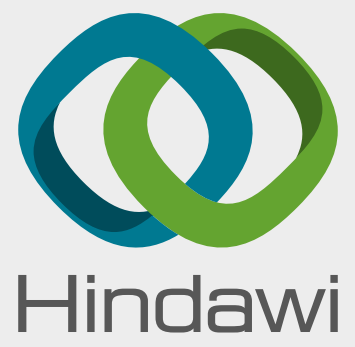

Submit your manuscripts at

www.hindawi.com
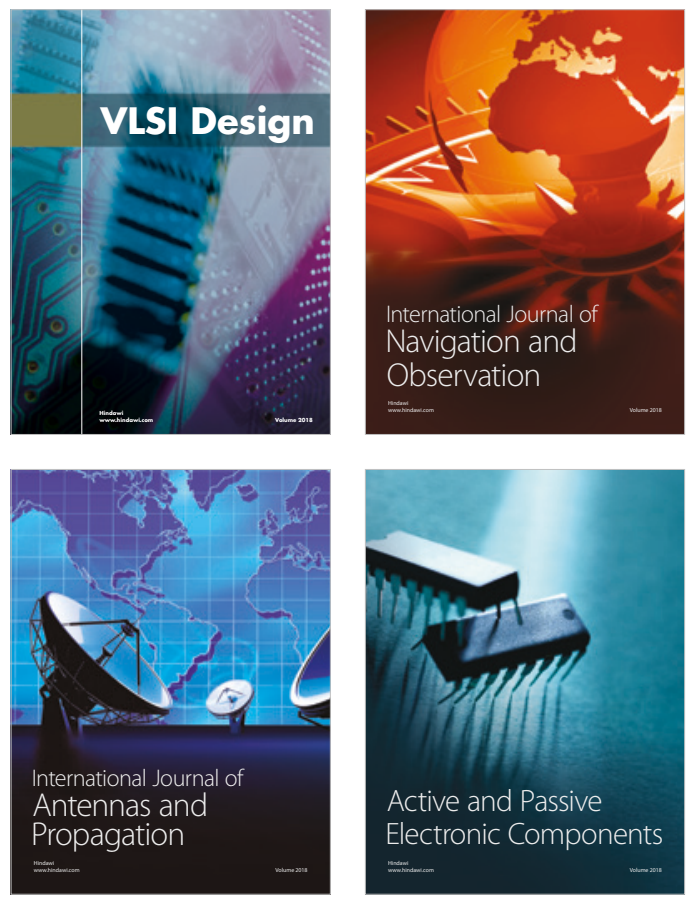
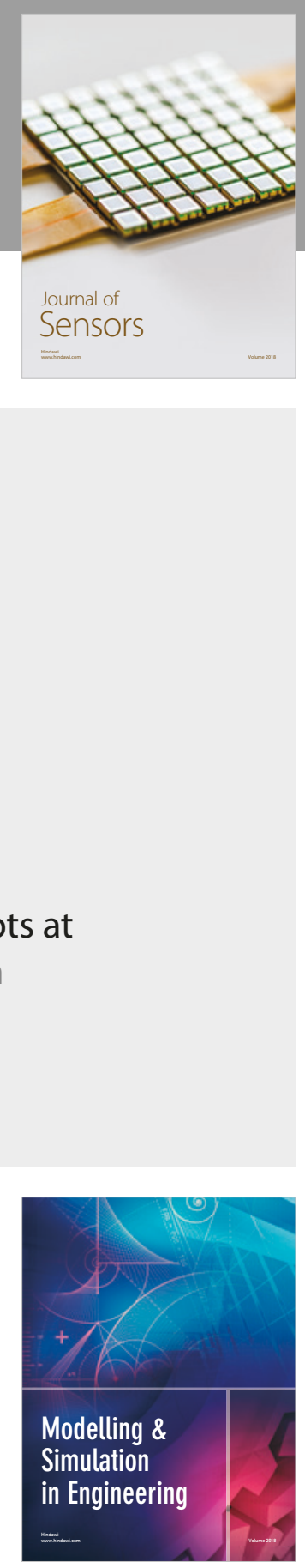

\section{Advances \\ Multimedia}
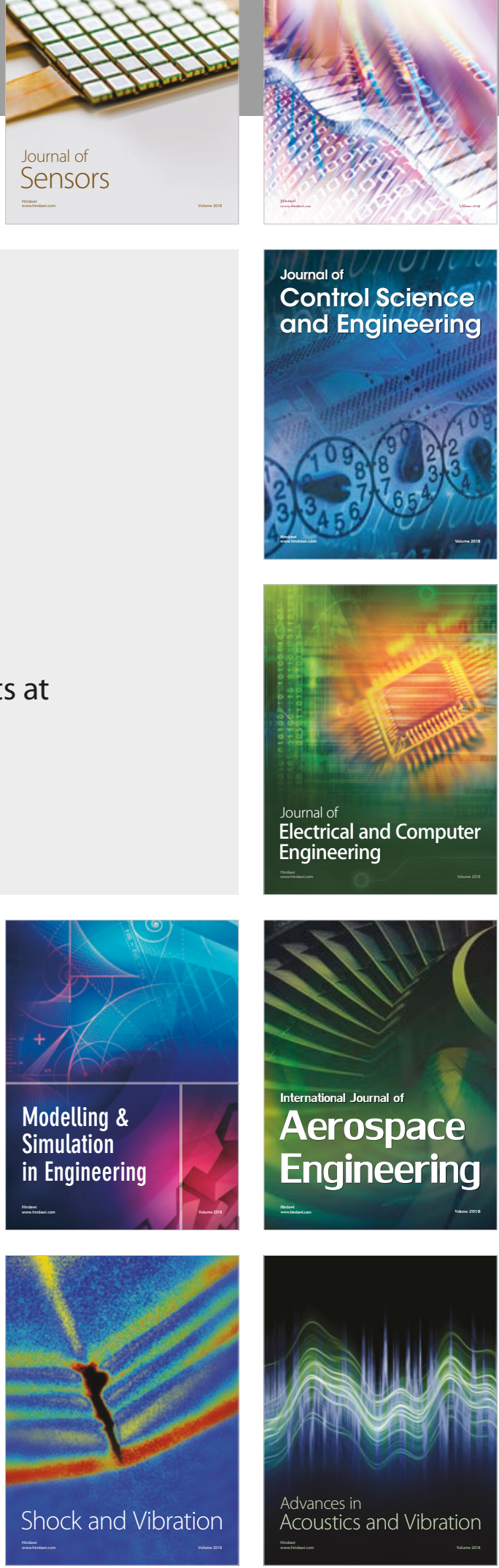